\section{Gregorio de Nisa y el ejercicio de inculturación de la teología*}

\section{Orlando Solano-Pinzón**}

RECIBIDO: 03-05-16. APROBADO: 07-09-16

Resumen: Este artículo continúa la indagación sobre el ejercicio de inculturación de la teología en el quehacer teológico de Gregorio de Nisa en su obra De vita Moysis. Se busca mostrar la forma como este autor dialogó con la cultura de su época y su aporte en el esfuerzo por hacer inteligible la fe cristiana. Como son muchos los elementos culturales implicados en su obra, se ofrece como ejemplo la referencia al mito de la caverna.

Palabras clave: Patrística, padres capadocios, mito de la caverna, Gregorio de Nisa, inculturación de la teología.
Gregory of Nyssa and the Exercise of Inculturation of Theology

ABstract: This article seeks to continue the research on the exercise of inculturation of Theology on the theological work of Gregory of Nyssa in his text De Vita Moysis. It attempts to point out how this author carried out the dialogue with the culture of his time and his contribution in the effort to make intelligible the Christian faith. Because of the huge amount of cultural elements involved in his work, the myth of the cavern is given as an example and a reference.

Key Words: Patristic; Cappadocian Fathers; Myth of the Cave; Gregory of Nyssa; Inculturation of Theology.

\section{PARA CITAR ESTE ARTÍCULO:}

Solano Pinzón, Orlando. "Gregorio de Nisa y el ejercicio de inculturación de la teologia”. Theologica Xaveriana 184 (2017): 509-532. https://doi.org/10.11144/javeriana.tx67-184.gneit

* Artículo de reflexión resultado de la investigación sobre la inculturación de la teología en Gregorio de Nisa (registro de investigación 00006874).

** Doctor en Teología, Pontificia Universidad Javeriana, Bogotá. Docente de tiempo completo de la Facultad de Teología de la misma universidad; miembro del grupo de investigación Academia. Orcid: 0000-0003-4446-626X. Correo electrónico: o.solano@javeriana.edu.co 


\section{Introducción}

Los padres de la Iglesia han sido reconocidos como ejemplo de inculturación por su trabajo denodado por hacer inteligible la fe al interior de la cultura grecorromana en la cual les correspondió vivir. Entre los padres que más evidenciaron este esfuerzo de diálogo con la cultura se encuentra Gregorio de Nisa, reconocido como columna de la ortodoxia $^{1}$ en el primer Concilio de Constantinopla, a quien el segundo Concilio de Nicea dio el apelativo de "Padre de los padres".

El estudio de su obra De vita Moysis en clave de inculturación ha permitido, hasta el momento, (1) contribuir en la elaboración de un marco conceptual que favorece la inculturación de la teología hoy33; (2) identificar los antecedentes, las características y los ejes fundamentales que orientaron la labor de inculturación del quehacer teológico del Obispo de Nisa en la cultura griega ${ }^{4}$; y (3) explicitar la paideia como estructura fundamental de su quehacer teológicos.

Dados los aportes anteriores, el presente artículo da cuenta de la continuidad del proceso investigativo sobre la inculturación de la teología en Gregorio de Nisa, mostrando la forma de apropiar los elementos de la cultura griega para argumentar en favor de la fe, concretamente, en referencia a la alegoría de la caverna. Para tal efecto, en un primer momento se realiza una breve contextualización de la obra $D e$ vita Moysis; a continuación se describe la primera teofanía en clave de alegoría de la caverna; en tercer lugar, se explicitan las características del ejercicio de inculturación llevado a cabo por el Obispo de Nisa a partir de los elementos del marco conceptual que orientó tal ejercicio ${ }^{6}$; y se finaliza con una conclusión.

Antes de proceder, conviene afirmar que el ejercicio de interpretación que sigue es personal y, por esta razón, en continuidad con la forma de proceder de Gregorio, se propone como una hipótesis abierta al buen sentido de quienes la examinen?

\footnotetext{
${ }^{1}$ Ortodoxia, en este contexto, hace referencia a la fidelidad a la fe proclamada en el Concilio ecuménico de Nicea (325). Según Severino González, "que en el Concilio fuera considerado como una de las columnas de la ortodoxia, se desprende del hecho de que, terminado este, Teodosio, por ley del 30 de julio de 381 (Cod. Theod., 16, 1, 3), excluía de las iglesias del Ponto como a herejes manifiestos a cuantos no estuviesen en comunión con Eladio de Cesárea, Otreyo de Melitene y Gregorio de Nisa" (Gonzalez, "La

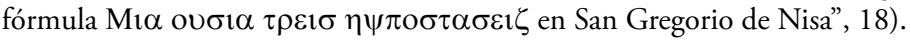

${ }^{2}$ Castellanos de Losada, Biografía eclesiástica completa, 399.

${ }^{3}$ Solano Pinzón, "Aporte del De vita Moysis de Gregorio de Nisa a la inculturación de la teología hoy", 325-360.

${ }^{4}$ Ídem, “Inculturación de la teología en Gregorio Nisa: antecedentes”, 157-183.

5 Ídem, "La paideia como estructura fundamental del quehacer teológico en Gregorio de Nisa", 229-244.

${ }^{6}$ Los elementos del marco conceptual fueron abordados en un artículo de la revista Franciscanum citado anteriormente, pero que en el presente artículo son abordados en función de la interpretación de primera teofanía.

${ }^{7}$ Mateo-Seco (ed.), Gregorio de Nisa. Sobre “La vida de Moisés”(Parte II, No. 173), 175, 176.
} 


\section{Una mirada a la obra De vita Moysis}

Quasten ubica De vita Moysis entre las obras exegéticas y la considera un tratado místico en el cual "Gregorio proporciona, bajo la forma de un retrato ideal de Moisés, una guía para la vida virtuosa". Para Eduardo Torres, la peculiaridad de De vita Moysis pudiera tomarse "por una obra de exégesis espiritual, por una biografía edificante, por un cuadro filosófico al estilo platónico, y algo de todo eso es. Sin embargo, estamos ante una exposición".

Algunas alusiones a su edad avanzada y al contenido de la obra en general bastan para probar que la escribió entre los años 390 y $392^{10}$, por lo cual es una obra del periodo de su madurez intelectual ${ }^{11}$. En cuanto al destinatario de la misma, no hay unidad de criterios: algunos sugieren los nombres de su hermano Pedro, obispo de Sebaste, o bien los de los monjes Olimpo o Cesario. A partir del estudio estructural realizado por Eduardo Torres, en la exposición de la obra, por el tipo de expresiones que usa, se puede suponer que el destinatario fue una persona de confianza, con quien Gregorio estaba familiarizado, poseedor de una fina sensibilidad espiritual, rasgos que apuntan hacia su hermano Pedro ${ }^{12}$.

La obra tiene como tema central la perfección del hombre ${ }^{13}$ y consta de dos partes, que muestran dos tipos distintos de exégesis escrituraria. La primera presta atención especial al sentido literal, ofreciendo un resumen de la vida de Moisés, según los libros de Éxodo y Números, con amplificaciones u omisiones, según parece en su sentido literal edificante, al estilo de la haggadá judía ${ }^{14}$. La segunda parte, que es la esencial, consiste en una interpretación alegórica ${ }^{15}$, por medio de la cual Gregorio

\footnotetext{
${ }^{8}$ Quasten, Patrología II, 138.

9 Torres Moreno, San Gregorio de Nisa: "De Vita Moysis": estudio estructural, 74.

${ }^{10}$ Mateo-Seco (ed.), Gregorio de Nisa, 17.

11 “Con esta obra se sitúa Gregorio en la cumbre de la 'teología' griega, donde la visión de Dios es la gran pasión terrena de cada hombre, como la única respuesta cabal a las cuestiones humanas definitivas sobre el sentido de la vida" (Torres Moreno, San Gregorio de Nisa, 87).

${ }^{12}$ Ibíd. 94.

${ }^{13}$ El tema de la perfección va a ser abordado por Gregorio en clave de epéktasis, que significa literalmente tensión hacia adelante, y hace referencia al crecimiento sin límites como característica irrenunciable de la verdadera virtud. “...toda la obra va a consistir en esto: en mostrar comentando los sucesos de la vida de Moisés que, en el caminar hacia Dios, a una etapa sigue siempre otra, y a una ascensión sucede siempre otra. No hay final" (Mateo-Seco, ed., Gregorio de Nisa, 23).

${ }^{14}$ Torres Moreno, Gregorio de Nisa, 85.

${ }^{15}$ Woìniakp, "El valor teológico-epistemológico del deseo humano de Dios en De vita Moysis de San Gregorio de Nisa”, 481.
} 
muestra la coherencia existente entre las diversas etapas de la vida de Moisés y la naturaleza de la perfección de la vida virtuosa, Según Jaeger:

Moisés aparece como el modelo perfecto del santo y del místico, el prototipo de lo que el Niseno llama la vida filosófica o contemplativa, el hombre cuya vida fue vivida en una incesante comunión con Dios, el hombre que ascendió a la cima de su Sinaí espiritual a fin de ver a Dios en la oscuridad de una nube. ${ }^{16}$

La lógica interna de la estructura de la obra está marcada por el camino que Moisés tiene que recorrer para poder encontrarse con Dios ${ }^{17}$. La vida es el camino de perfeccionamiento. La metáfora del camino expresa bien la naturaleza humana: el hombre es un buscador que no puede tranquilizarse sin encontrar lo que está buscando. El comienzo de su caminar es la inquietud de un ser finito que encuentra en sí un dinamismo que le empuja hacia lo infinito ${ }^{18}$.

Importa la conexión entre el acercamiento a Dios y la vida en cuanto historia, es decir, en cuanto secuencia de hechos concretos. La historia de la vida, es decir, la vida vista como proceso, como dinamismo continuo, es la materia prima del quehacer teológico del Niseno, ya que permite la conexión con la economía divina, en tanto a Dios es posible acercarse por medio de sus obras, y ello contribuye a avanzar en su conocimiento (teología). ${ }^{19} \mathrm{El}$ fin del itinerario es comprender que todo lo visible tiene escondido, en sus entrañas, lo invisible. La invisibilidad es el aura de lo visible, y lo visible existe para ser huella y antorcha del viaje hacia lo invisible ${ }^{20}$.

\section{El ejercicio de inculturación de la teología}

Antes de mostrar cómo el Obispo de Nisa aborda el ejercicio de inculturación de la teología, conviene evocar la comprensión de esta expresión, tratada en publicaciones anteriores, para contextualizar mejor el presente apartado: se entiende por inculturación de la teología "el proceso de apropiación de una matriz cultural, para repensar, decir, vivir y celebrar desde ella, la manera como se desoculta Dios en los acontecimientos de la historia que viven las mujeres y los hombres que comparten dicha matriz" ${ }^{21}$.

\footnotetext{
${ }^{16}$ Jaeger, Cristianismo primitivo y paideia griega, 132-133.

17 "Filón había escrito una Vida de Moisés y, con ello, proporcionó a San Gregorio su modelo literario. Pero después completa su imagen de Moisés con la ferviente vida de su propia espiritualidad mística" (ibíd., 133). Según Mateo-Seco, con Filón llega a su máxima expresión el engrandecimiento de la figura de Moisés en el judaísmo (Mateo-Seco, ed., Gregorio de Nisa, 24).

${ }^{18}$ Woìniakp, "El valor teológico-epistemológico del deseo humano de Dios en De vita Moysis de San Gregorio de Nisa”, 483.

${ }^{19}$ Ibíd. 483.

${ }^{20}$ Ibíd. 491.

${ }^{21}$ Solano, "Inculturación de la teología en Gregorio Nisa”, 162.
} 
En esta breve descripción conceptual es de gran importancia la referencia a la apropiación de la matriz cultural en el proceso de inculturación, pues -según Robira Belloso- "una cultura solo puede ser fecundada desde dentro, desde su libertad, no desde fuera y desde el dominio exterior ejercido con medios puramente humanos". ${ }^{22}$

A partir de esta comprensión y de los antecedentes ${ }^{23}$ que están en la base de su ejercicio (que en Gregorio de Nisa remiten al contexto sociopolítico y económico de la Capadocia de la segunda mitad del siglo IV, al contexto eclesiástico, a la configuración de su experiencia de fe, a la influencia de su ambiente familiar, a la educación recibida y a la experiencia pastoral vivida), es posible acercarse al ejercicio de inculturación plasmado en el De vita Moysis.

\section{El quehacer teológico de Gregorio en el De vita Moysis}

Intentar explicitar la manera de apropiar los elementos de la cultura por parte de Gregorio es una tarea compleja pues -como señala Daniélou- "él no suele citar a los pensadores paganos. Es en el estudio de los textos donde podremos encontrar una luz" ${ }^{24}$. Por eso ofrecemos a continuación un ejemplo de apropiación cultural en función de argumentar en favor de la fe a partir de la referencia al mito de la caverna con la cual inicia el Libro VII de La República de Platón.

En esta referencia a los mitos es importante tener presente la aclaración de Daniélou ${ }^{25}$ sobre el uso de los mismos por parte de Gregorio:

El lenguaje platónico, sobre todo el de los mitos, le ofrece, en competencia con la Biblia, un tesoro de expresiones para sus auditorios y sobre el cual describe el misterio único, pues habla de la transformación del alma en Jesús-Cristo.

Ahora bien, el Obispo de Nisa, como buen conocedor de la cultura griega, comprendía que esta se había desarrollado transformando sus bases previas, no destruyéndolas; y por ello no buscó destruir su cultura, y en ella, las ideas filosóficas ${ }^{26}$ y teológicas que la sostenían, sino transformarlas desde la novedad que aportaba la fe

${ }^{22}$ Rovira, Introducción a la teología, 327.

${ }^{23}$ Los antecedentes del ejercicio de inculturación en Gregorio de Nisa fueron publicados en la revista Theologica Xaveriana, en el artículo ya citado.

${ }^{24}$ Daniélou, "Orientations actuelles de la recherche sur Grégoire de Nysse", 3.

${ }_{25}$ Ídem, Platonisme et théologie mystique: essai sur la doctrine spirituelle de Saint Grégoire de Nysse, 9.

${ }^{26}$ Peroli, en sintonía con Dörrie, afirma que Gregorio conocía el juego de los filósofos de su tiempo y jugaba con ellos hasta un determinado límite, debido a que ellos no habían sido iluminados por la revelación (Reale y Peroli, Platonismo e cristianesimo. ¿Antagonismo o comuni fondamenti?, 125). 
cristiana $^{27}$. En este caso, dado que la estructura del teologizar del Niseno está marcada por la idea de paideia, echa mano de la obra de Platón, fuente de la paideia griega de su época, para desde ella dar cuerpo a la paideia cristiana ${ }^{28}$.

Es importante tener presente que en la perspectiva de la comprensión de la paideia platónica, la que tiene como referente Gregorio de Nisa, la meta de toda comunidad humana es lograr el máximo desarrollo del alma del individuo, es decir, educarlo para convertirlo en una personalidad humana completa ${ }^{29}$. Además, que según Jaeger, fue Gregorio de Nisa quien "transfirió las ideas de la paideia griega, en su forma platónica, a la vida del movimiento ascético que se originó durante su época en el Asia Menor y en el Cercano Oriente y que pronto iba a desplegar un inesperado poder de atracción" ${ }^{30}$.

Platón había utilizado el mito de la caverna ${ }^{31}$ como explicación alegórica de la situación en la cual se encuentra el hombre respecto al conocimiento ${ }^{32}$ y para demostrar cómo los grados del conocimiento no están presentes en la misma persona, sino que cada persona pasa de un grado al otro muy lentamente, con gran esfuerzo. El caminar de un grado a otro requiere de una conversión, de un cambio completo de la mentalidad, que haga posible el paso del mundo sensible al inteligible, y de la opinión, de la pasión, a la ciencia y al bien ${ }^{33}$. La filosofía busca conducir a los hombres a la conversión de un grado al otro hasta el grado supremo, donde solo se tiene conocimiento verdadero de la realidad ${ }^{34}$.

Gregorio interpreta la primera teofanía (zarza que no se apaga) que se presenta en la vida de Moisés desde la perspectiva de la alegoría de la caverna; pero desde una apropiación muy personal, tal como afirma Elisa Ferrer ${ }^{35}$ : “...su pensamiento

${ }^{27}$ Según Von Balthasar, Gregorio de Nisa mejor que ningún otro supo traducir la herencia espiritual de la antigua Grecia al modo cristiano (Von Balthasar, Présence et pensée. Essai sur la philosophie religeuse de Grégoire de Nysse: "Introducción", xiii-xiv).

${ }^{28}$ La explicitación de la forma de apropiar la noción de paideia por parte de Gregorio se encuentra publicada en la revista Veritas, Vol. 32, en artículo ya citado.

${ }^{29}$ Divenosa y Mársico, Platón. La República, 327-388.

${ }^{30}$ Jaeger, Cristianismo primitivo y paideia griega, 138.

${ }^{31}$ Divenosa y Mársico, Platón, 445-450.

${ }^{32}$ Reale y Antiseri, Historia del pensamiento filosófico, 153,154.

${ }^{33}$ Zamperini, Platone: un maestro del pensiero occidentale, 60.

${ }^{34}$ Mondin, Storia della metafisica I, 165.

${ }^{35}$ Ferrer, "Preposiciones y esquemas simbólicos en De vita Moysis de Gregorio de Nisa", 35. También Daniélou afirma: "Gregorio no ha permitido ninguna discrepancia entre su teología y su trasfondo, la teología metafísica de los platónicos. Lo que estaba en contradicción lo ha dejado de lado, casi siempre con cuidadosa fundamentación" (Daniélou, "Grégoire de Nysse et la philosophie”, 28-39. La traducción es nuestra). 
cristiano desbordó esas formas concretas ya existentes, determinando modos propios de expresión, que contribuyeron a dar forma a una profunda experiencia espiritual".

Por tal razón, Gregorio no cita el Libro VII de La República de Platón, pero para quien vive en medio de una cultura en la cual la paideia tiene como fuente la obra de Platón, fácilmente establecerá la similitud con la interpretación de los hechos que anteceden y dan cuerpo a la primera teofanía ${ }^{36}$.

Para efectos del objeto de nuestro estudio, nos detendremos en mostrar la estructura que confiere el Obispo de Nisa a su interpretación de la primera teofanía en clave de alegoría de la caverna en términos de la condición del hombre bajo el dominio de las pasiones, la condición del hombre que se libera del dominio de las pasiones y la condición del hombre después de liberarse del dominio de las pasiones. El hilo conductor es la explicación del paso del pecado a la gracia o -con los términos utilizados por el Niseno- el paso de la purificación de la opinión en torno de aquello que no es (es decir, lo aparente, lo material, lo pasional sensible, que no tiene subsistencia por sí mismo) al conocimiento de aquello que es, en este caso, la verdad (inteligible), Dios mismo.

Primera teofanía: la zarza ardiendo

Condición del hombre bajo el dominio de las pasiones:

Lo femenino de la vida, aquello que el tirano quiere que sobreviva, es la índole material y pasional hacia la que es conducida, al resbalar, la naturaleza humana. ${ }^{37}$

Quienes entregan sus hijos al tirano, los exponen desnudos y sin protección a la corriente. Entiendo por corriente la vida agitada con sucesivas pasiones; lo que cae en esta corriente, hundiéndose, se sumerge en ella, y se ahoga. ${ }^{38}$

Si somos demasiado débiles para asumir por nosotros mismos el triunfo de la verdad, y el mal prevalece con sus argumentos y rechaza el primado de la verdad, hemos de huir de aquí lo más rápidamente posible siguiendo la imagen del modelo que la historia de Moisés nos propone para conducirnos hacia una enseñanza de los misterios de la fe ${ }^{39}$.

Para Gregorio, la naturaleza humana caída trajo como consecuencia para el hombre el revestimiento de un cuerpo animal (túnicas de piel) con sus pasiones y placeres sensibles. Señala Daniélou ${ }^{40}$ :

\footnotetext{
36 "Gregorio reinterpreta refiriéndolo en relación con la vida presente, de la cual es necesario ser liberados" (Mateo-Seco y Maspero, eds., Diccionario sobre Gregorio de Nisa, 220).

${ }^{37}$ Mateo-Seco (ed.), Gregorio de Nisa, (Parte II, No. 2), 32.

${ }^{38}$ Ibíd. (II, 6), 33.

${ }^{39}$ Ibíd. (II, 16), 36.

${ }^{40}$ Daniélou, Le IV siecle Gregoire de Nysse et son milieu, 97. La traducción es nuestra.
} 
Las túnicas de piel son una marca de la condescendencia de Dios. Dios quiere que el hombre se vuelva libremente hacia él. Los hombres quieren atarse a los bienes sensibles y Dios orientará este atractivo a su bien. Las túnicas de piel permiten que experimenten el mal y darle la espalda libremente. Ellas son indiferentes; susceptibles de ser utilizadas por el pecado como por la virtud.

En relación con lo anterior es oportuno aclarar que, para el Obispo de Nisa, tanto el cuerpo como la vida presente no son, de ninguna manera, en sí mismos, una cárcel o una fosa, como era propio de la comprensión de personajes como Plotino o Porfirio, sino que -como afirma Maspero- "la caverna oscura es la condición humana caída después del pecado original”"11.

La condición del hombre que se libera del dominio de las pasiones:

Cuando estemos dedicados a esta paz y a este reposo, la verdad nos aclarará e iluminará con sus propios destellos los ojos del alma. Esta verdad que se ha manifestado en la misteriosa aparición que tuvo lugar en ese entonces, es Dios mismo. ${ }^{42}$

La primera enseñanza que nos deja esta iluminación es qué tenemos que hacer para permanecer dentro de los rayos de la luz verdadera: que no es posible correr con los pies calzados hacia la altura donde brilla la luz de la verdad, sino que es necesario despojar los pies del alma del revestimiento de pieles muertas de la que fue revestida la naturaleza en los orígenes, cuando fuimos desnudados a causa de la desobediencia a la voluntad divina. Si hacemos esto, el conocimiento de la verdad se manifestará así mismo, ya que el conocimiento de lo que es, se convierte en purificación de la opinión en torno a lo que no es. ${ }^{43}$

\section{La condición del hombre después de liberarse del dominio de las pasiones:}

Moisés llegó entonces a esto, y ahora llega también todo hombre que, como él, se despoje de su envoltura terrena y mire hacia la luz que sale de la zarza, hacia el rayo lleno de espinas, figura de la carne que ha brillado para nosotros y que es, como nos dice el Evangelio, la verdadera luz y la verdad.

Un hombre así es capaz de ayudar a los otros en orden de la salvación, destruir la tiranía del mal y encaminar hacia la libertad a quien está bajo la tiranía de la esclavitud. Los milagros de la mano derecha y la transformación del bastón en serpiente constituyen la primera manifestación. ${ }^{44}$

Esta manera de apropiar la estructura del mito de la caverna facilita la identificación de las diferencias radicales que se establecen con la interpretación dada por

\footnotetext{
${ }^{41}$ Mateo-Seco y Maspero (eds.), Diccionario sobre Gregorio de Nisa, 221.

${ }^{42}$ Mateo-Seco (ed.), Gregorio de Nisa, (II, 19), 37.

${ }^{43}$ Ibíd. (II, 22) 38.

${ }^{44}$ Ibíd. (II, 26) 39.
} 
Platón: para Gregorio, en términos epistemológicos, el conocimiento de lo verdadero, de lo que tiene consistencia en sí mismo, del ser al que relaciona con Dios, viene dado por revelación a la cual se accede por medio de la fe.

En términos ontológicos, parte del dato revelado y se identifica con la revelación de Dios, cuyo culmen se encuentra en la encarnación del Hijo, acontecimiento al cual se refiere en términos de luz y verdad en la interpretación del símbolo de la zarza.

En términos gnoseológicos, el conocimiento de Dios requiere descalzarse, acción que remite a despojarse de las túnicas de piel o, en otros términos, a la experiencia de purificación, con su doble faceta de apartamiento del mal y de elección del camino recto, que dispone al encuentro con la verdad. La figura de la zarza que no se consume, por medio de la cual Dios se manifiesta a Moisés, permite comprender que el conocimiento que Moisés recibe de Dios es fruto de la iniciativa divina que le sale al encuentro. No en vano, para los padres de la Iglesia, el verdadero conocimiento viene de la fe.

Además, la metafísica a la que hace referencia Gregorio trasciende la lógica de la alegoría de la caverna, que ejemplifica la metafísica platónica, debido a que está abierta a la cuestión de Dios y tiene como fuente la Escritura. Esta comprensión se hace evidente en cómo Gregorio interpreta la escena de la zarza como manifestación de Dios, particularmente, de la encarnación del Logos de Dios. La particularidad que asume la metafísica -en la interpretación del Niseno- da cuenta de la transformación que ha hecho de la matriz cultural (paideia griega) sobre la cual realiza la interpretación en función de una comprensión profundamente cristiana (paideia cristiana).

El trasfondo ético también va a ser muy particular, ya que el referente para Gregorio es Moisés, no un filósofo pagano. La figura de Moisés había sido exaltada, desde tiempo atrás, por Filón de Alejandría, quien había elaborado ya una obra sobre este personaje para presentarlo como modelo de filósofo. En el caso del Obispo de Nisa, la intención es presentarlo como modelo de creyente, de hombre virtuoso y como prefiguración de Cristo.

\section{Características del ejercicio de inculturación presentes en la primera teofanía}

\section{Uso de la Escritura}

La referencia a la Escritura es fundamental para Gregorio en tanto que constituye la paideia cristiana ${ }^{45}$. Si bien la obra inicia con la pregunta de en qué consiste la perfec-

${ }^{45}$ Desde la comprensión de la Escritura como paideia, la figura de "Moisés aparece como el modelo perfecto del santo y del místico, el prototipo de lo que el Niseno llama la vida filosófica o contemplativa, 
ción en la virtud, la fuente que le permite acercarse a la respuesta es la Escritura. A ella se acerca desde una interpretación literal, para dar cuerpo a toda la primera parte de su obra, recogiendo los datos que permitan elaborar un relato histórico de secuencia de los pasos por los cuales Moisés se acerca a Dios ${ }^{46}$.

Por este motivo, lo importante es la conexión entre el acercamiento a Dios y la vida en cuanto historia, es decir, en cuanto secuencia de hechos concretos ${ }^{47}$. Dicho relato es el referente de la interpretación alegórica de la segunda parte de la obra, a la cual Gregorio recurre para encontrar el sentido espiritual. La teofanía de la zarza que no se consume constituye el referente que le permite interpretar el paso del conocimiento de lo sensible, lo material, lo aparente, al conocimiento de lo que tiene consistencia en sí mismo, de la verdad, de Dios ${ }^{48}$.

Además, en el ejercicio de la interpretación alegórica, el Niseno recurre a la Escritura como autoridad para fundamentar su interpretación; esto se puede evidenciar en la interpretación de la escena en la que Moisés recibe la misión de liberar al pueblo de la esclavitud: como muestra de la fuerza recibida de Dios, al dejar caer su bastón, este cobra vida, y al tomarlo una vez más, vuelve a su estado original; y cuando Moisés saca su mano del seno, esta se transforma en un copo de nieve; así mismo, cuando introduce de nuevo su mano en el seno, vuelve a su aspecto natural ${ }^{49}$. Estos prodigios son interpretados por el Obispo de Nisa como expresión simbólica del misterio de la encarnación, para lo cual apela a la Escritura:

Me orienta hacia esta interpretación el testimonio profético y evangélico. Pues el profeta dice: Este es el cambio de La diestra del Altísimo (Sal 77,11), como si la Divinidad, considerada inmutable, se hubiese mudado conforme a nuestro aspecto y figura por condescendencia para con la debilidad de la naturaleza humana [...]. El cambio de bastón en serpiente no ha de turbar a los amigos de Cristo como si tuviésemos que armonizar la palabra del misterio con un

el hombre cuya vida fue vivida en una incesante comunión con Dios, el hombre que ascendió a la cima de su Sinaí espiritual a fin de ver a Dios en la oscuridad de una nube" (Jaeger, Cristianismo primitivo y paideia griega, 131-132).

${ }^{46}$ Para Gregorio es claro que "las vidas de los grandes hombres están puestas como ejemplo de virtud para la posteridad" (Mateo-Seco, ed., Gregorio de Nisa [II, 48] 123).

${ }^{47}$ La historia de la vida comprendida como un proceso, como un dinamismo continuo, constituye la materia prima del teologizar del obispo de Nisa.

${ }^{48}$ Según Balderas, la Sagrada Escritura es, para el obispo de Nisa, "la guía de la razón (Contra Eunomio $1,114)$, el criterio de la verdad, y supone una ventaja sobre la sabiduría de los paganos" (Balderas, Jesús, cristianismo y cultura en la Antigüedad y en la Edad Media, 175). Para Trevijano, la Escritura en Gregorio interviene como "criterio seguro de la verdad para distinguir en las opiniones así formadas las que le son conformes y las que le son ajenas" (Trevijano, Patrología, 210).

${ }^{49}$ Mateo-Seco (ed.), Gregorio de Nisa (I, 21), 76. 
animal que se le opone. La verdad misma no rechaza esta imagen cuando dice con la voz del Evangelio: Como Moisés levantó la serpiente en el desierto, asi es necesario que sea levantado en alto el Hijo del Hombre (Jn 3,14). ${ }^{50}$

\section{Referencia a la tradición}

El ejercicio de inculturación de la teología no solo encuentra autoridad en la Escritura, sino también reconoce la importancia de la tradición para salvaguardar la continuidad del legado de la fe recibida. La referencia a Orígenes es innegable, aunque conviene afirmar que Gregorio echa mano del aporte de los autores con un espíritu de libertad en función de su interés particular. Para Orígenes, como para Gregorio, la figura de Moisés "es el ejemplo de los perfectos que han alcanzado espiritualmente el conocimiento del Padre en el Hijo" ${ }^{51}$.

Según Méhat ${ }^{52}$, al estructurar los comentarios a la vida de Moisés, el Niseno sigue de cerca el esquema de la Homilía 27 de Orígenes al libro de Números, en la cual aplica la división en etapas del largo camino del éxodo a las diversas etapas del caminar del alma hacia Dios. Si bien este postulado es válido, para Daniélou ${ }^{53}$, la división del itinerario de Moisés hacia Dios en tres etapas es propia del Niseno, quien ha aplicado dicha estructuración previamente en la Homilía XI sobre el Cantar de los Cantares.

Al inicio de la exposición de la segunda parte, Gregorio hace uso de la comparación de lo femenino, referido a lo material y pasional, con lo masculino de la vida, referido a lo rudo y fuerte de la virtud, como elementos constitutivos de la naturaleza humana, para señalar que lo femenino es lo que el tirano quiere que sobreviva. Esta comparación proviene de las homilías sobre el éxodo de Orígenes ${ }^{54}$ y el libro sobre preguntas y respuestas sobre el éxodo de Filón de Alejandrías5.

Pues ¿quién desconoce que todo ser que esté sujeto al cambio no permanece nunca idéntico a sí mismo, sino que continuamente pasa de un estado a otro,

${ }^{50}$ Ibíd. (II, 28.31), 116-118.

${ }^{51} \mathrm{Harl}$, Origène et la fonction révélatrice du Verbe lncarné, 167. La traducción es nuestra.

${ }^{52}$ Méhat, Origène. Homèlies sur les nombres, 511-557.

${ }^{53}$ Daniélou, Platonisme et theologie mystique, 17-23.

${ }^{54}$ Fortier y De Lubac, Origène. Homélies sur l'Exode, II. 3, 98. "Los egipcios, a los cuales el faraón había dado sus órdenes, dejaban vivir solamente a las mujeres; ellos detestan a los varones, porque odian la virtud y no alimentan los vicios y los placeres" (ibíd. La traducción es nuestra).

${ }^{55}$ Marcus, Philo. Questions and Answers on Exodus, I. 8, 15-16. "Simbólicamente, como he dicho, esto indica progreso perfecto y al mismo tiempo el varón. Para el progreso es de hecho nada más que el dar del género femenino por carga en el macho, puesto que el género femenino es material, pasivo, corpóreo y sentido-perceptible, mientras que el macho es activo, racional, incorpóreo y más parecido a la mente y el pensamiento" (ibíd. La traducción es nuestra). 
pues la mudanza siempre se opera hacia mejor o hacia peor? Aplíquese esto a nuestro asunto. Lo femenino de la vida, aquello que el tirano quiere que sobreviva, es la índole material y pasional hacia la que es conducida, al resbalar, la naturaleza humana; en cambio, el retoño varonil es lo rudo y fuerte de la virtud, que es hostil al tirano y que a este le resulta sospechoso de rebelión contra su poder. ${ }^{56}$

Después de afirmar que en la naturaleza mudable en la cual se encuentra el hombre nada permanece totalmente idéntico a sí mismo, el Niseno aborda el tema de la libertad como posibilidad para escoger entre el varón o la hembra, la virtud o el vicio. Este planteamiento tiene como trasfondo la teoría de los dos caminos que se encuentra en la Didaché y en la Carta de Bernabé ${ }^{57}$. Según Quasten ${ }^{58}$, este postulado remite a una concepción griega conocida desde antaño, utilizada en las sinagogas helenísticas para instruir a los prosélitos.

Ser sujeto de cambio es nacer continuamente, pues en la naturaleza mudable no se da nada que permanezca totalmente idéntico a sí mismo. Pero, ser engendrado de este modo no proviene de un impulso exterior, a semejanza de los que engendran corporalmente lo que no prevén, sino que es el resultado de nuestra libre elección, por tanto, somos, en cierto sentido, nuestros propios padres: nos engendramos a nosotros mismos conforme a lo que queremos ser. Mediante la voluntad, nos conformamos al modelo que escogemos: varón o hembra, virtud o vicio. ${ }^{59}$

Las narraciones de la riña entre un hebreo y un egipcio, en la que Moisés toma partido por el compatriota, y de la pelea sostenida por dos hebreos, en la que Moisés busca evitar la contienda entre hermanos ${ }^{60}$, Gregorio las interpreta como los dos caminos o como el buen espíritu y el mal espíritu sobre los cuales debe decidir el hombre en el ejercicio de su libertad. Para afianzar su interpretación apela a la doctrina del ángel custodio, difundida desde los inicios del cristianismo ${ }^{61}$, en los siguientes términos:

\footnotetext{
${ }^{56}$ Mateo-Seco (ed.), Gregorio de Nisa (II, 2), 105.

${ }^{57}$ Ropero, Lo mejor de los padres apostólicos, 93; 280.

${ }^{58}$ Quasten, Patrología I, 39.

${ }^{59}$ Mateo-Seco (ed.), Gregorio de Nisa (II, 3), 106.

${ }^{60}$ Ibíd. (II, 18), 73-74.

${ }^{61}$ Esta referencia a la figura del ángel se encuentra en el libro de los Hechos 12,13-15: "Llamó él a la puerta y salió a abrirle una sirvienta llamada Rode; quien, al reconocer la voz de Pedro, de pura alegría no abrió la puerta, sino que entró corriendo a anunciar que Pedro estaba a la puerta. Ellos le dijeron: 'Estás loca'. Pero ella continuaba afirmando que era verdad. Entonces ellos dijeron: 'Será su ángel'”.
} 
Para no explicar unos enigmas por medio de otro enigma, expondré más abiertamente el sentido de este pasaje. Existe una doctrina que merece credibilidad por pertenecer a la tradición de los padres. Dice que, tras la caída de nuestra naturaleza en el pecado, Dios no contempló nuestra desgracia indiferentemente, sino que colocó cerca, como ayuda para la vida de cada uno, a un ángel que ha recibido una naturaleza incorpórea; y que en la parte opuesta, el corruptor de la naturaleza maquinó algo parecido, dañando la vida del hombre mediante un demonio perverso y malvado. ${ }^{62}$

\section{Centralidad del misterio de la encarnación}

Para Gregorio de Nisa, como para todos los padres de la Iglesia, hace posible la teología el conocimiento de Dios, que Dios mismo en su infinito amor quiso manifestarse a los seres humanos y que el misterio de la encarnación es la máxima realización de dicha comunicación de Dios ${ }^{63}$. Por este motivo, la referencia a la encarnación está a la orden del día en el anuncio del Evangelio que permea su labor pastoral y el ejercicio de hacer inteligible la fe. Concretamente, la teofanía de la zarza va a ser interpretada por Gregorio como manifestación del misterio de la encarnación que hace posible el verdadero conocimiento de la verdad, de Dios.

A diferencia de la alegoría de la caverna, en la que el conocimiento de la verdad es resultado del esfuerzo de la razón, en el caso de Moisés, dicho conocimiento viene dado por revelación de Dios mismo. Al respecto afirma Gregorio:

Y cuando estemos dedicados a esta paz y a este pacifico reposo, entonces brillara la verdad, llenando de luz con sus propios destellos los ojos del alma. Dios mismo es la verdad que se manifestó entonces a Moisés a través de aquella inefable iluminación [...]. Este pasaje nos enseña el misterio de la Virgen: la luz de la divinidad, que gracias a su parto ilumina desde ella la vida humana, ha guardado incorrupta la zarza que ardía, sin que la flor de la virginidad se agostase en el parto. ${ }^{64}$

\section{Carácter trinitario}

En el teologizar del Niseno la referencia al misterio trinitario es recurrente, a tal punto que, según Daniélou, "él es el gran autor de la trascendencia divina. Él da a

\footnotetext{
${ }^{62}$ Mateo-Seco (ed.), Gregorio de Nisa (II, 45), 122.

${ }^{63}$ Para Gregorio de Nisa, como para toda la tradición oriental, la encarnación está unida a la redención y es imposible disociarlas al punto de que la redención supone la encarnación y la encarnación tiene como cumbre la redención. En este sentido, es en la medida que el Verbo es verdaderamente hombre que el hombre es verdaderamente salvado (Daniélou, Le IV siecle, 111-114). El texto clave en la comprensión nisena de la encarnación es el de Jn 1,14: "el Verbo se hizo carne".
}

${ }^{64}$ Mateo-Seco (ed.), Gregorio de Nisa (II, 19.21), 112-113. 
la doctrina de analogía su expresión filosófica más profunda [...]. En él, la teología trinitaria definida por el Concilio de Nicea, encuentra su expresión más acabada" ${ }^{65}$.

Especialmente, en el contexto de la teofanía de la zarza señala que quienes eligen el camino de la virtud y avanzan en el conocimiento de lo que tiene consistencia en sí mismo, no están solos, sino cuentan con la ayuda de Dios para sobreponerse a las dificultades propias del camino. Al respecto, en la interpretación del encuentro con el ángel, Gregorio se expresa en los siguientes términos:

A quien está dedicado al progreso en la virtud, le asiste una ayuda dada por Dios a nuestra naturaleza, que es anterior a nosotros en cuanto a su origen, pero que se muestra y se da a conocer cuando nos aprestamos a combates más fuertes, tras habernos familiarizado suficientemente con cuidado y diligencia con la vida más elevada. ${ }^{66}$

\section{Carácter comunitario eclesial}

En la lógica de la alegoría de la caverna, la búsqueda del conocimiento de la verdad es un ejercicio individual pues resulta del esfuerzo exclusivo de la razón. En la narración que hace parte de la primera teofanía queda al descubierto la importancia que tiene la referencia a la comunidad en el camino hacia la virtud y al conocimiento de la verdad, de Dios. En su interpretación, Gregorio pone en evidencia el carácter comunitario eclesial de su teologizar; ejemplo de ello es la interpretación del hecho de que Moisés, a pesar de vivir con la hija del faraón, continuaba alimentándose de la leche de la madre natural, y el Niseno concluye:

...si en el tiempo de nuestra educación convivimos estrechamente con los pensamientos paganos, debemos no apartarnos de la leche de la Iglesia, que nos alimenta. La leche son los preceptos y costumbres de la Iglesia, con los que el alma se alimenta y se fortifica, tomando de aquí el punto de partida para subir hacia lo alto. ${ }^{67}$

\section{El teólogo como testigo}

En Gregorio de Nisa la educación cumple un papel determinante, tanto en el ejercicio teológico como en el apostólico ${ }^{68}$. En la interpretación de la cestilla en la cual los

\footnotetext{
${ }^{65}$ Daniélou, Le IV siecle, 25.

${ }^{66}$ Mateo-Seco (ed.), Gregorio de Nisa (II, 44), 122.

${ }^{67}$ Ibíd. (II, 12) 109.

68 "Gregorio recurre en sus obras, una y otra vez, al concepto de educación que era, por así decirlo [...] el ideal a priori de toda la reflexión griega sobre este problema: el concepto de morphosis. Su constante repetición de esta imagen básica, que implica la identidad esencial de toda actividad educativa y la obra
} 
padres de Moisés lo depositan para liberarlo de la muerte, la referencia directa es la educación, que cumple la función de cestilla sobre las olas de la vida, para lograr que la persona se mantenga a flote y evitar que se equivoque mucho y se hunda.

Esa arqueta, tejida con mimbres diversos, es la educación, tejida a su vez con diversas disciplinas; sobre las olas de la vida, ella mantendrá a flote a aquel que lleva.

Gracias a ella, este no errará mucho por la agitación de las aguas, llevado de un lado a otro por el movimiento de las olas, sino que habiendo llegado a la estabilidad de la tierra firme, esto es, habiendo salido de la agitación de la vida, será empujado hacia lo estable por el impulso mismo de las aguas. ${ }^{69}$

Además, al interpretar la escena en la cual Moisés, después de haber vivido la experiencia de iluminación en la zarza, habla al pueblo valerosamente acerca de la libertad, la enseńanza con la cual concluye es: "Que no debe atreverse a hablar ante el pueblo aquel que no haya cultivado su forma de decir con una educación adecuada para dirigirse a muchos" ${ }^{\prime \prime}$.

Lo anterior permite comprender mejor la importancia de la educación para Gregorio, que incluye el conocimiento y la vida virtuosa. Más aún, él es consciente de que muchos de los que han accedido al ministerio no se han preparado debidamente, tienen ambición por los cargos eclesiásticos y, por esta razón, son foco de división y opiniones heréticas.

\section{La búsqueda de sentido espiritual}

Según el Obispo de Nisa, la teología es un ejercicio espiritual de inteligencia de la fe; y para realizar dicho ejercicio, toda la realidad está habilitada debido a que desde el misterio de la encarnación fue asumida en el Hijo y anhela su salvación. Por tal razón, la realidad cumple una función reveladora que necesita ser interpretada, para esclarecer el sentido espiritual que le subyace y contribuye a posibilitar el conocimiento de Dios y la vida virtuosa. El sentido espiritual de la primera teofanía lo interpreta Gregorio desde el aprendizaje de Moisés a partir de la contemplación de la luz, para quien solo Dios es el que es, solo él es lo verdaderamente existente.

El ejemplo en el cual se puede verificar la referencia al esfuerzo por indagar el sentido espiritual se encuentra en el momento de interpretar el encuentro de Moisés

del artista creador, pintor, escultor, revela la naturaleza plástica de su concepción de la paideia griega” (Jaeger, Cristianismo primitivo y paideia griega, 121-122).

${ }^{69}$ Mateo-Seco (ed.), Gregorio de Nisa (II, 7.8), 107-108.

${ }^{70}$ Ibíd. (II, 55), 126. 
con Aarón, quien aparece en la escena en procura de su ayuda, y Gregorio afirma: "Para no explicar unos enigmas por medio de otro enigma, expondré más abiertamente el sentido de este pasaje" 71 .

\section{El método}

En el teologizar del Niseno, en función de dar cuenta del sentido espiritual, el método seguido es la akolouthia, entendida como una coherencia, secuencia de racionamientos de carácter explicativo y argumentativo que aseguran el carácter científico del conocimiento por medio de la reducción a los primeros principios ${ }^{72}$. En la segunda parte de la obra, Gregorio parte de los datos de la historia de Moisés, y desde allí inicia el esfuerzo por desentrañar el sentido espiritual y el carácter orgánico de la vida espiritual a partir de una secuencia coherente de razonamientos, con argumentos que retoma de su formación y del medio cultural. Para el caso de la primera teofanía, que constituye el objeto de nuestro escrito, el dato histórico de la vida de Moisés recoge información desde su nacimiento hasta el acontecimiento de la zarza.

En el desarrollo de su exposición, Gregorio suele hacer evidente la lógica de su proceder. En concreto, tras explicar la interpretación de la mujer que acompaña a Moisés, quien ha sido tomada de un pueblo extranjero, se expresa en los siguientes términos:

...a quien esté iniciado en la interpretación de la historia, le será patente, por cuanto se ha dicho, la continuidad del progreso en la virtud que muestra el discurso siguiendo paso a paso la concatenación de los acontecimientos simbólicos de la historia. ${ }^{73}$

\section{Centralidad cristológica}

El Niseno, en coherencia con la impronta cristocéntrica de su teología ${ }^{74}$, interpreta el pasaje de la zarza ardiendo en términos encarnatorios y soteriológicos, pues para él estos se encuentran íntimamente unidos ${ }^{75}$ : Dios, a quien reconoce como verdad y como luz,

${ }^{71}$ Ibíd. (II, 45) 122.

${ }^{72}$ Daniélou evoca la comprensión de la akolouthia citando algunas expresiones de Gregorio que le permiten afirmar, dada la persistencia en el uso, del método utilizado: "La concatenación de esto que ha sido explicado antes, conduce nuestros discursos a la inteligencia de este pasaje. Más aún: tal es el sentido que me parece contiene este paso, que es sugerido por la secuencia de las explicaciones dadas anteriormente. La repetición misma de las expresiones muestra que aquí se trata, para Gregorio, de un método al cual retoma siempre" (Daniélou, L'essere e il tempo in Gregorio di Nissa, 30. La traducción es nuestra).

${ }^{73}$ Mateo-Seco (ed.), Gregorio de Nisa (II, 39), 120.

${ }^{74}$ Daniélou, Platonisme et théologie mystique, 27.

${ }^{75}$ Mateo-Seco y Maspero (eds.), Diccionario sobre Gregorio de Nisa, 247. 
"se nos ha manifestado a través de la carne" 76 . Y es enfático en afirmar que la luz divina ilumina sobre todo en el misterio de la encarnación del Logos: es en Cristo donde la luz brilla más que en todos los astros del cielo, y gracias a él tiene lugar la destrucción del tirano y la liberación de quienes este oprime. Respecto del misterio de la encarnación, Daniélou afirma:

El principio de toda unión del alma individual con el Verbo es la unión del Verbo con la naturaleza humana. Por la encarnación, el Verbo ha santificado toda la naturaleza humana, pero esta vida divina que es en lo sucesivo como un fermento en la humanidad, concebida como un solo cuerpo, debe propagarse en cada uno de sus miembros. ${ }^{77}$

Además, interpreta el símbolo de la zarza que arde como representación de las dos naturalezas de Cristo, esto es, la luz de Dios que se ha revelado por medio de la carne y el misterio de la concepción virginal ${ }^{78}$.

\section{Un ejercicio narrativo, especulativo y mistico}

En la primera teofanía se hace evidente la versatilidad con la cual el Obispo de Nisa hace uso del lenguaje para interpretar la vida de Moisés. Dicha versatilidad se mueve entre el lenguaje narrativo, el lenguaje especulativo y el lenguaje místico. Esta riqueza de manejo del lenguaje no quiere decir que toda teología inculturada deba apropiarlos, pero sí que, cuando se trata de hacer inteligible la experiencia de la fe, no hay que escatimar esfuerzos que lo hagan posible.

Gregorio hace gala de su libertad en el manejo de sus fuentes; las usa en función del interés que dio origen al escrito, referido a la perfección en la virtud. En la medida en que se avanza en la interpretación, será la secuencia coherente de razonamientos la que le exija -en razón de la argumentación- el tipo de lenguaje a utilizar. En concreto, el lenguaje narrativo será más recurrente, no solo porque la interpretación gira en torno de la vida de Moisés, sino porque -como buen teólogo-implica su vida en el discurso. A continuación, se señalan algunos ejemplos que dan cuenta del uso del lenguaje narrativo:

Moisés nació precisamente cuando el tirano había ordenado matar a los varones. ¿Cómo imitaremos con nuestra libre elección las circunstancias del nacimiento de este hombre? No está en nuestro poder -dirá seguramente alguien-imitar aquel ilustre nacimiento con nuestro nacimiento [...]. La experiencia nos

\footnotetext{
${ }^{76}$ Mateo-Seco, Gregorio de Nisa (II, 20), 113.

77 Daniélou, Platonisme et théologie mystique, 36. La traducción es nuestra.

${ }^{78}$ Mateo-Seco y Maspero (eds.), Diccionario sobre Gregorio de Nisa, 256.
} 
enseña también esto: que la inestabilidad y el cambio constante de los negocios rechazan lejos de si a quienes no están inmersos en los engaños humanos, como considerando una carga inútil a quienes les son molestos por su virtud [...]. Por consiguiente, cuando uno ha convivido con la reina de los egipcios, aunque no parezca excluido de sus magnificencias, debe correr hacia la que es madre por naturaleza, de la cual [Moisés] no se apartó en el tiempo de su crianza junto a la reina, ya que fue amamantado, como recuerda la historia, con la leche materna. Esto enseña, a mi parecer, que si en el tiempo de nuestra educación convivimos estrechamente con los pensamientos paganos, debemos no apartarnos de la leche de la Iglesia, que nos alimenta. ${ }^{79}$

En el esfuerzo por argumentar las opciones de su interpretación, el Niseno ve necesario apelar al lenguaje especulativo:

A mi parecer, esta es la definición de la verdad: no errar en el conocimiento del ser. El error es una ilusión que se produce en el pensamiento en torno a lo que no es, como si lo que no existe tuviese consistencia, mientras que la verdad es un conocimiento firme de lo que verdaderamente existe [...]. En efecto, aunque la mente considere diversos aspectos en los seres, el pensamiento no ve a ninguno de ellos con tal suficiencia que no necesite nada de otro, es decir, con tal suficiencia que le sea posible existir sin participar en el ser. Lo que siempre es de igual forma, lo que ni crece ni disminuye, lo que no se mueve a ningún cambio, ni hacia mejor ni hacia peor (él es, en efecto, ajeno a lo peor y no hay nada mejor que él); lo que no tiene necesidad de nada ajeno, aquello que es lo único deseable, lo que es participado por todos y que no queda disminuido con esa participación: eso es lo que verdaderamente existe y cuya contemplación es el conocimiento de la verdad. ${ }^{80}$

Y cuando el acontecimiento a interpretar lo requiere, hace uso del lenguaje místico:

De esta luz aprendemos lo que tenemos que hacer para permanecer dentro de los resplandores de la luz verdadera: que no es posible correr con los pies calzados hacia aquella altura en la cual se contempla la luz de la verdad, sino que es necesario despojar los pies del alma de su envoltura de pieles, muerta y terrena, de la que fue revestida la naturaleza en el principia, cuando fuimos desnudados a causa de la desobediencia a la voluntad divina. ${ }^{81}$

\section{Un servicio a la Iglesia}

Inculturar la teología es un servicio que se presta a la Iglesia en su esfuerzo por encarnarse en la realidad histórica. La teología nació in medio Ecclesiae y al servicio de la

\footnotetext{
${ }^{79}$ Mateo-Seco (ed.), Gregorio de Nisa (II, 1.9.12), 105, 108, 109.

${ }^{80}$ Ibíd. (II, 23. 25), 114, 115.

${ }^{81}$ Ibíd. (II, 22), 114.
} 
Iglesia frente a la necesidad de hacer inteligible la experiencia de la fe. La mayoría de escritos del Obispo de Nisa surgieron de solicitudes frente a necesidades propias del contexto en el cual estaba inmerso. Especialmente De vita Moysis busca responder a la pregunta que le hicieron a Gregorio sobre la perfección en la virtud.

En el desarrollo de la primera teofanía queda plasmado el sentido de dicho servicio en la persona de Moisés, quien después de ser iluminado por la luz verdadera, que es el Verbo, queda capacitado para ayudar a los demás en procura de la salvación, que constituye el mensaje central de la Iglesia, como cuerpo de Cristo. En las otras dos teofanías se hará aún más evidente el tipo de servicio que presta Moisés al pueblo.

Moisés llegó entonces a esto, y ahora llega también todo aquel que, siguiendo su ejemplo, se despoja a sí mismo de su envoltura terrena y mira a la luz que sale de la zarza, esto es, al rayo de luz que nos ilumina a través de la carne llena de espinas, que es, como dice el Evangelio, la luz verdadera y la verdad. Entonces ese llega a ser capaz de prestar ayuda a los demás en orden a la salvación, de destruir la tiranía de aquel que domina con malas artes, y de encaminar hacia la libertad a quien está bajo la tiranía de la perversa esclavitud. ${ }^{82}$

\section{Diálogo entre teología y cultura}

La actitud de Gregorio ante la cultura pagana es abierta, porque conoce las bondades que ofrece, y al mismo tiempo cauta, por las desviaciones en las que se puede incurrir. Mateo-Seco señala que, en la teología de Gregorio, todos los aportes de la cultura sirven como recurso para hacer avanzar la inteligencia de la $\mathrm{fe}^{83}$.

Las referencias a la carta que dirige Orígenes a Gregorio Thaumaturgo, en la cual le hace recomendaciones sobre el uso de la cultura pagana ${ }^{84}$, y a la carta de Basilio a los jóvenes ${ }^{85}$, donde les pone en conocimiento los beneficios y peligros propios

${ }^{82}$ Ibíd. (II, 26) 116.

${ }^{83}$ Para mayor información, ver a Mateo-Seco y Maspero (eds.), Diccionario sobre Gregorio de Nisa, 235.

84 "Pero quiero que utilices toda la fuerza de tus disposiciones naturales en función de la doctrina cristiana. En cuanto a los medios a emplear, quiero que tomes de la filosofía griega todo lo que pueda servir como enseñanza encíclica o propedéutica para introducir al cristianismo y, de igual manera, de la geometría y la astronomía todo aquello que sea útil a la interpretación de la Escritura Santa [...]. Puede ser una idea semejante a la sugerida por un pasaje del Éxodo. Dios en persona hace decir a los hijos de Israel de pedirles a los vecinos y compañeros de habitación los vasos de plata y de oro, así como los vestidos. Ellos deberán, de esta manera, despojar a los egipcios para encontrar en esto el material que servirá a la organización del culto divino" (Grégoire le Thaumaturge, Remerciement a Origène suivi de la lettre d'Origène a Grégoire, 187-189. La traducción es nuestra).

85 "Se dice en el texto que el gran Moisés, famoso en el mundo por su sabiduría, que solo después de haber ejercitado la mente en las ciencias de los egipcios, se dio a la contemplación del ser. Y como él, pero en una época más reciente, dicen que el sabio Daniel había aprendido en Babilonia la sabiduría de los caldeos y se había dedicado después al estudio de las cosas divinas [...]. Escogeremos aquellos escritos 
de la cultura pagana, están presentes en Gregorio y, por ello, ante la necesidad de interactuar en medio de dicha cultura, recomienda alimentarse con los preceptos y costumbres que proporciona la Iglesia.

He aquí algunos ejemplos. La filosofía pagana enseña que el alma es inmortal, pero enseña también que transmigra de unos cuerpos a otros, y que pasa de la naturaleza racional a la irracional: esto es una incircuncisión carnal y extranjera. Y así muchas otras cosas. Enseña la existencia de Dios, pero por otro lado lo cree material; confiesa que es demiurgo, pero ańade que necesita la materia para crear el mundo; le atribuye bondad y poder, pero somete el bien de las cosas a la limitación del destino. ${ }^{86}$

Por consiguiente, cuando uno ha convivido con la princesa de los egipcios, aunque no parezca excluido de sus magnificencias, debe correr hacia la que es madre por naturaleza, de la cual Moisés no se apartó en el tiempo de su crianza junto a la princesa, ya que fue amamantado, como recuerda la historia, con la leche materna. Esto nos enseña, a mi parecer, que, si frecuentamos la cultura pagana en el tiempo de nuestra educación, no debemos apartarnos de la leche que nos nutre, que es la Iglesia. La leche son los sacramentos que alimentan nuestra alma, la fortalecen y le dan fuerza para elevarse hacia lo alto. ${ }^{87}$

En la interpretación de la procedencia extranjera de la esposa de Moisés se encuentra el criterio que está en la base del diálogo con el mundo, con la cultura. $\mathrm{Si}$, en virtud de la encarnación, la realidad quedó transida de la trascendencia y cumple por ello una función reveladora de la misma, el criterio para viabilizar el diálogo antes mencionado consiste en que contribuya a engendrar la virtud y el conocimiento de Dios. Por tanto, si la apropiación y el diálogo con la cultura deben realizarse de manera crítica, dicha crítica se orienta a discernir eso que haga posible la apertura a la fe y la vivencia de la misma.

Él será acompañado por su mujer, nacida de una raza extranjera. Hay en la cultura profana algo que no es posible rechazar en la formación en la virtud. La filosofía moral y la filosofía de la naturaleza pueden ayudar a quienes les gustan y las cultivan a elevarse más alto, a condición de que su fruto no retenga nada de la mancha extranjera. ${ }^{88}$

en los cuales es alabada la virtud y condenado el vicio [...]. Creo que es bueno que los jóvenes de su edad imiten este ejemplo, que sustancialmente concuerda con nuestros principios. El comportamiento de Sócrates, de hecho, es muy similar a nuestro mandamiento que prescribe colocar la otra mejilla a quien nos golpea" (Basilio di Cesarea, "Come leggere i classici. Consigli ai giovani”. La traducción es nuestra).

${ }^{86}$ Mateo-Seco (ed.), Gregorio de Nisa (II, 40), 120.

${ }^{87}$ Ibíd. (II, 12), 109.

${ }^{88}$ Ibíd. (II, 37) 119-120. 


\section{A manera de conclusión}

El ejercicio de inculturación realizado por Gregorio de Nisa permite dar cuenta de los diferentes elementos que entran en juego a la hora de dar razón de la fe y hacer avanzar la inteligencia de la misma. En el esfuerzo de interpretación de la primera teofanía se hizo evidente la importancia que Gregorio confiere a una buena educación como arqueta que permite no errar tanto en la búsqueda de la verdad.

$\mathrm{Al}$ respecto, el amplio conocimiento que el Obispo de Nisa tenía de la cultura de su época le permitió encontrar, en el mito de la caverna, el referente adecuado para interpretar los hechos de la vida de Moisés que anteceden y dan cuerpo a la primera teofanía. El análisis realizado hizo posible comprender y afirmar que, en el uso del lenguaje propio de la filosofía, el Niseno no se limitó a emular de manera literal lo que otros habían dicho, sino que se movió con un espíritu de libertad y creación, fijando su atención en el contenido de la fe que se está mediando a través de la historia de Moisés y no en lo plasmado por los filósofos.

Así, puede entenderse mejor por qué Gregorio no cita a los autores paganos, ya que la apropiación que realiza de los planteamientos de los filósofos hace que se transforme el sentido que tenían las categorías filosóficas. Ello determina modos propios de expresión que apelan a la argumentación bíblica, en aras de hacer avanzar la inteligencia de la fe y responder a la pregunta que dio origen a la obra.

Las características del ejercicio de inculturación de la teología que se han explicitado a partir de la interpretación de la vida de Moisés son una forma de dar cuenta de los diferentes elementos que hicieron parte del teologizar de Gregorio, que pueden servir como insumo y fuente de inspiración para responder a la necesidad urgente de inculturar la teología hoy. Además, dichas características pueden ayudar a evitar la tendencia de nuestro tiempo de volver la mediación filosófica lo fundamental, con menoscabo de la Sagrada Escritura y la tradición.

La inculturación de la teología es posible gracias al misterio de la encarnación. Cristo, al encarnarse, se ha unido en cierto modo a todo ser humano y por ello la fe puede ser fermento de todas las culturas. Además, este ejercicio de inculturación es un ejercicio siempre en construcción, debido a diversos factores, entre otros, los siguientes: ser obra del ser humano, quien por su condición de finitud está sometido a la contingencia, a la posibilidad del error; el carácter dinámico de la historia y de la cultura; la condición infinita e inabarcable de la naturaleza divina; la limitación permanente de los conceptos para dar cuenta de la manifestación de Dios; la dinamicidad de la fe y su deseo de una mayor comunión con Dios: porque la inteligencia de la fe está limitada por las circunstancias históricas y culturales de cada época, y porque las fuentes de la teología exigen ser continuamente interpretadas para resignificarse, de 
acuerdo con los contextos, y para ampliar cada vez más la comprensión del sentido espiritual que les subyace.

En últimas, el trabajo de interpretación realizado en el presente artículo es un aporte, entre los muchos que pueden darse, que no tiene pretensiones de agotar el tema, pero sí de retomar un camino de reencuentro con la tradición de los padres de la Iglesia, para aprender de ellos el talante que exige el ejercicio inaplazable de inculturación de la teología comprendido en clave de encarnación.

\section{Bibliografía}

Balderas Vega, Gonzalo. Jesús, cristianismo y cultura en la Antigüedad y en la Edad Media. México: Universidad Iberoamericana, 2007.

Basilio di Cesarea. "Come leggere i classici. Consigli ai giovani". Martino Sanna, http://www.martinosanna.de/materiali/Basilio_di_Cesarea.pdf (consultado el 27 de marzo de 2016).

Castellanos de Losada, Basilio Sebastián. Biografía eclesiástica completa. Vol. 23. Madrid: Imprenta de Alejandro Gómez Fuentenebro, 1868.

Daniélou, Jean. "Grégoire de Nysse et la philosophie". En Gregor von Nyssa und die Philosophie. Zweites Internationales Kolloquium über Gregor von Nyssa, Freckenhorst bei Münster 18-23 September 1972, editado por Herausgegeben von Heinrich Dörrie, Margarete Altenburger y Uta Schramm, 3-18. Leiden: E. J. Brill, 1976.

. L'essere e il tempo in Gregorio di Nissa. Roma: Arkeios, 2000.

. Le IV siecle: Gregoire de Nysse et son milieu. Paris: Institut Catholique, 1974.

. "Orientations actuelles de la recherche sur Grégoire de Nysse". En Écriture et culture philosophique dans la pensée de Grégoire de Nysse, Actes du Colloque de Chevetogne (22-26 september 1969), editado por Marguerite Harl, 3-17. Leiden: E. J. Brill, 1971.

. Platonisme et théologie mystique: essai sur la doctrine spirituelle de Saint Grégoire de Nysse. Paris: Aubier, 1944.

Divenosa, Marisa y Claudia Mársico. Platón. La República. Buenos Aires: Losada, 2005.

Ferrer, Elisa. "Preposiciones y esquemas simbólicos en De vita Moysis de Gregorio de Nisa". Revista de estudios clásicos 33 (2006): 33-51.

Fortier, Phillippe y Henri de Lubac. Origène. Homélies sur l'Exode. Paris: Du Cerf, 1947. 
Gonzalez, Severino. "La fórmula Mı ov $\sigma \iota \alpha \tau \rho \varepsilon \imath \sigma \eta \psi \pi о \sigma \tau \alpha \sigma \varepsilon ı \zeta$ en San Gregorio de Nisa”. Analecta Gregoriana Vol. XXI (1939) 1-146.

Grégoire le Thaumaturge. Remerciement a Origène suivi de la lettre d Origène a Grégoire. Paris: Du Cerf, 1969.

Harl, Marguerite. Origène et la fonction révélatrice du Verbe Incarné. Paris: Du Seuil, 1958.

Jaeger, Werner y Elsa Cecilia Frost. Cristianismo primitivo y paideia griega. Breviarios Vol. 182. México: Fondo de Cultura Económica, 1974.

Marcus, Ralph. Philo. Questions and Answers on Exodus. Cambridge (MA): Harvard University Press, 1953.

Mateo-Seco, Lucas Francisco. (ed.). Gregorio de Nisa. Sobre "La vida de Moisés". Biblioteca de Patrística 23. Madrid: Ciudad Nueva, 1993.

Mateo-Seco, Lucas Francisco. y Giulio Maspero (eds.). Diccionario sobre Gregorio de Nisa. Burgos: Monte Carmelo, 2006.

Méhat, André. Origène. Homèlies sur les Nombres. París: Du Cerf, 1951.

Mondin, Battista. Storia della metafisica. Vol. 1. Bolonga: Edizioni Studio Domenicano: 1998.

Quasten, Johannes. Patrología. I. Hasta el Concilio de Nicea. Madrid: Biblioteca de Autores Cristianos, 1968.

- Patrología. II. La edad de oro de la literatura patrística griega. Madrid: Biblioteca de Autores Cristianos, 1985.

Reale, Giovanni y Dario Antiseri. Historia del pensamiento filosófico. 3 vols. Barcelona: Herder, 2010.

Reale, Giovanni y Enrico Peroli. Platonismo e cristianesimo. ¿Antagonismo o comuni fondamenti? Milano: Vita e Pensiero, 1993.

Ropero, Antonio. Lo mejor de los padres apostólicos. Barcelona: Clie, 2004.

Rovira Belloso, José María. Introducción a la teología. Madrid: Biblioteca de Autores Cristianos, 1996.

Solano Pinzón, Orlando. "Aporte del De vita Moysis de Gregorio de Nisa a la inculturación de la teología hoy". Franciscanum 163, Vol. LVII (2015): 325-360. . "Inculturación de la teología en Gregorio Nisa: antecedentes." Theologica Xaveriana 179 (2015): 157-183. Disponible en: http://dx.doi.org/10.11144/ javeriana.tx65-179.itgn (consultado el 27 de marzo de 2016). 
. "La paideia como estructura fundamental del quehacer teológico en Gregorio de Nisa". Veritas 32 (2015): 229-244.

Torres Moreno, Eduardo. San Gregorio de Nisa: "De Vita Moysis": estudio estructural. Madrid: Universidad Complutense, 2005.

Trevijano Etchevarria, Ramón. Patrología. Madrid: Biblioteca de Autores Cristianos, 1994.

Von Balthasar, Hans Urs. Présence et pensée. Essai sur la philosophie religeuse de Grégoire de Nysse. Paris: Beauchesne, 1942.

Woìniakp, Robert. "El valor teológico-epistemológico del deseo humano de Dios en De vita Moysis de San Gregorio de Nisa”. Scripta Theologica 38/2 (2006): 473-499.

Zamperini, Luciano. Platone. Un maestro del pensiero occidentale. Firenze: Gruppo Editoriale, 2003. 